\title{
Apparel Recommendation System Evolution: An empirical review
}

\author{
${ }^{1}$ Congying Guan, ${ }^{1}$ Shengfeng Qin, ${ }^{1}$ Wessie Ling, ${ }^{2}$ Guofu Ding \\ ${ }^{1}$ Department of Design, Northumbria University, UK \\ ${ }^{2}$ Southwest Jiaotong University, Chengdu, P.R.China \\ Congying.guan@gmail.com
}

\section{Abstract \\ Purpose}

With the developments of e-commerce markets, novel recommendation technologies are becoming an essential part of many online retailers' economic models to help drive online sales. Initially, this paper undertakes an investigation of apparel recommendations in the commercial market in order to verify the research value and significance. Then, this article reviews apparel recommendation techniques and systems through academic research, aiming to acquaint apparel recommendation context, summarize the pros and cons of various research methods, identify research gaps, and eventually propose new research solutions to benefit apparel retailing market.

\section{Design/methodology/approach}

This study utilizes empirical research drawing on 130 academic publications indexed from online Databases. We introduce a three-layer descriptor for searching articles, and analyse retrieval results via distribution graphics of years, publications, and keywords.

\section{Findings}

This study classified high-tech integrated apparel systems into 3D CAD systems, personalized design systems, and recommendation systems. Our research interest is focused on recommendation system. Four types of models were found, namely clothes searching/retrieval, wardrobe recommendation, fashion coordination and intelligent recommendation systems. The forth type, smart systems, has raised more awareness in apparel research as it is equipped with advanced functions and application scenarios to satisfy customers. Despite various computational algorithms were tested in system modelling, existing research lacks of concerns in terms of apparel and users profiles research. Thus, from the review, we have identified and proposed a more complete set of key features for describing both apparel and users profiles in a recommendation system.

\section{Originality/value}

Based on previous studies, this is the first review paper on this topic in this subject field. The summarised work and the proposed new research will inspire future researchers with various knowledge backgrounds, especially, from a design perspective.

Keywords

Apparel retailing, Apparel recommendation system, Apparel design, Knowledge learning, Features extraction

\section{Introduction}

In apparel retailing, a new trend of smart shopping is highlighted aiming to improve customer experiences and increase sales, with several new technologies support, such as virtual try-on for clothing display, smart recommendation for clothes searching and selection. 3D virtual try-on is one of the typical applications based on 3D garment design and simulation technology. It could display the style looks on your digital body with your movements in front of a camera. Online shopping is an application scenario in which people acquire dressing looks and fit information without physically trying on clothes, such as Metail (Metail, 2012). Apparel recommendation is another state-of-the-art application in smart shopping context. Most of existing recommendation systems is to predict similar products that users may like from buying/like history based on data mining technology. The novel systems integrate fashion experts' knowledge to advice new products according to the customer body image, preferences, wearing occasions and clothing coordination. Wong et al. (2009b) emphasised that providing mix-and-match recommendation is a 'must' strategy for fashion retailers to enhance customer service and improve sales. This paper gives a scalable overview of the entire context of smart 
technology based systems targeted in apparel retailing. Researches on apparel recommendation systems have been comprehensively reviewed through both academic literatures and commercial applications.

General recommendation technology has been widely integrated into e-commerce websites in order to recommend books, music CDs, movies and news articles et al., such as amazon.com (Amazon, 1996) and the Netflix DVD-rental (NETFLIX, 1997). The main function of a general recommendation system is to predict products that potential consumers might want to buy based on their stated preferences, online shopping choices, and purchases of people with similar tastes or demographics (Leavitt, 2006). It consists of two system types, called content-based systems and collaborative filtering systems (Rajaraman and Ullman, 2011). Content-based systems examine properties of the recommended items by conducting a classification of users and products profile data according to the product features. Collaborative filtering systems recommend items based on similarity measures between users and/or items through clustering products bought from similar users. These systems recommend products on the basis of prediction of users' preferences by analysing a large scalable database from users' activities recorded through purchase or browse history, click rate, products questionnaire and user profiles.

In apparel recommendations, there is a distinctive function which is not only recommending similar products to meet users' current dressing-style, but providing personalized styling advice to develop better understanding of personalized styling. A survey indicated that $94 \%$ of the respondents admitted that their clothing purchasing decisions rely upon advice from others, such as friends and family (Yan et al., 2011b). As we can see, personal style advisor is much needed for ordinary people with less fashion knowledge and/or individual tastes in dressing. In the UK market, some companies, e.g. John Lewis (JohnLewis, 2001) and Be Styled UK (Bestyleduk, 2014) offer personal styling services to recommend appropriate clothes from in-person stores database. However, these services are costly and not applicable for e-business market. Electronic Commerce on the web is thriving, but consumers still have trouble finding products that meet their needs and desires (Shen et al., 2007). With tens of thousands of cloth styles in current online stores, it is challenging for a stylist to find appropriate clothes to match individual needs and occasional needs. In addition, the recommendation result highly depends on a stylist's personal knowledge and practical experiences.

Inspired by traditional styling services, researches on smart apparel recommendation systems mostly aim at recommending appropriate apparel to specific individuals based on rules mined from design knowledge and experts' experiences with computer intelligence methods. A recommendation technology vendor, ExpertMaker's CEO also indicated that some vendors added encoded knowledge into their systems to reflect the expertise of a skilled salesperson (Leavitt, 2006). This paper will review both traditional style similarity based apparel searching systems and style knowledge learning based intelligent apparel recommendation/ advisor systems.

The remaining of this paper is organised as follows: Section 2 gives an overview of apparel recommendation markets. Section 3 outlines our literature review methods. The main contributions of this paper are described in Section 4, including research findings in terms of system classifications in apparel retailing, developments of apparel recommendation systems, system modelling approaches and research gaps analyses. New research solutions with in-depth analysis of the apparel and user profiles are conducted in section 5. Final section summarised the review work.

\section{Apparel recommendation market overview}

A raising number of apparel online retailing of both womenswear and menswear are realizing that providing personalized product recommendation is a strategy of improving shopping experiences, bringing big traffic and increasing sales. A list of existing commercial systems is shown in table 1 . As we can see, various websites and mobile applications are appearing rapidly since 2011, which reflects the high market demand of such a smart shopping scenario. Three basic types of recommendation agents are identified, machine agents, human agents 
and hybrid agents recommendations. In the table 1, there are 21 existing systems, in which 5 systems use machine agents, 14 systems use human agents and 2 systems use hybrid agents for recommendation. The system capabilities are somehow dependant on system models (or types)

\begin{tabular}{|c|c|c|c|c|c|}
\hline Platforms & $\begin{array}{l}\text { Recommendation } \\
\text { agents }\end{array}$ & $\begin{array}{l}\text { System } \\
\text { types }\end{array}$ & Data collections & $\begin{array}{l}\text { Application } \\
\text { types }\end{array}$ & References \\
\hline Amazon & System automatic & Machine agent & User history data & Web & (Amazon, 1996) \\
\hline Styleup & System automatic & Machine agent & User history data & App & (Styleup, 2012) \\
\hline Nosto & System automatic & Machine agent & User history data & App & (Nosto, 2011) \\
\hline Stylebook & System automatic & Machine agent & User history data & App & (Stylebook, 2009) \\
\hline Mallzee & System automatic & Machine agent & Quiz & App & (Mallzee, 2012) \\
\hline StyleMatic & Friends & Human agent & Social media & App & (StyleMatic, 2013) \\
\hline Netrobe & Friends & Human agent & Social media & App & (Netrobe, 2011) \\
\hline Polyvore & Stylists \& Celebrities & Human agent & Social media & Web \&App & (Polyvore, 2007) \\
\hline ASOS stylists & Online stylists & Human agent & Quiz \& Skype chat & Web & (ASOS, 2014) \\
\hline Dressli & Online stylists & Human agent & Mobile chat & App & (Dressli, 2014) \\
\hline Glamour Ask a Stylist & Online stylists & Human agent & Mobile chat & App & (Askastylist, 2010) \\
\hline Trunk Club & Online stylists & Human agent & Quiz \&Skype chat & Mail & (TrunkClub, 2013) \\
\hline The Chapar & Online stylists & Human agent & Call & Mail & (Thechapar, 2013) \\
\hline Stitch Fix & Online stylists & Human agent & Quiz & Mail & (StitchFix, 2011) \\
\hline Baukjen & Online stylists & Human agent & Quiz \&Skype chat & Web & (BAUKJEN, 2014) \\
\hline Like To Know & Bloggers/Celebrities & Human agent & None & App & (LikeToKnow, 2016) \\
\hline Be Styled UK & Live stylists & Human agent & Face to face chat & Web & (Bestyleduk, 2014) \\
\hline Style doctor & Live stylists & Human agent & Face to face chat & Web & (Styledoctors, 2004) \\
\hline John Lewis & Live stylists & Human agent & Face to face chat & Web & (JohnLewis, 2001) \\
\hline Style Seek & System Interactions & Hybrid agent & Quiz & Web & (Styleseek, 2015) \\
\hline Dressipi & System Interactions & Hybrid agent & Quiz & Web & (dressipi, 2011) \\
\hline
\end{tabular}

Machine recommendations with machine agents are introduced earlier and still provided by several recommendation technology vendors and a few startups. For instance, the large retailer, Amazon, offers automatic recommendation functions based on user history data. Similarly, Nosto and Styleup are two startups only targeted on apparel retailing. Machine agents have the ability to contribute cross-selling and up-selling, shopping experiences and even customer engagement and loyalty. But they need data support and therefore, there are several barriers leading to some large retailers shied away from offering automated recommendations. First, many developers are struggling by lack of data, data collecting, filtering and complex data processing algorithms. Sentient Technologies reported that duo to fragmented data/profiles, marketers stuck on basic data for personalization (eMarketer, 2015). Second, the quality of recommendations is hard to convince customers to trust the recommendation results by simply tracking users history without knowing their shopping intentions or individual tastes. The Aaronson Group CEO Jack Aaronson (Grau, 2009) argued that a deeper understanding is necessary from knowing what the user did buy to why the user did buy something.

In contrast, the word-of-mouth recommendations with human agents by peers, friends as well as fashion professionals earned more trusts. The eMarketer indicated that the person making the recommendation is more valuable than the machine tracking user history and profiles (Grau, 2009). Peer recommendations are functioned among the raising social shopping sites such as StyleMatic (2013), Netrobe (2011) and Polyvore (2007). Peers such as friends, mates, or even strangers who share lifestyle or experiences all have better knowledge or understanding of the users. However, it is impossible to offer real-time immediate recommendation results as efficient as machine engines. Recommendations by fashion professionals are running by face-to-face, web, mobile and email stylists as well as bloggers and celebrities, e.g. ASOS (2014), Dressli (2014), Glamour Askastylist (2010), TrunkClub (2013), Thechapar (2013) and LikeToKnow (2016). Face to face chat with personal shoppers, such as Styledoctors (2004), is the original mode of personalized recommendation. It could offer high quality recommendations but its high cost made a very few people would use it. It also does not meet online shopping scenarios. Free services such as free online personal stylist advisor provided by ASOS (2014) as referring to the users' feedback (Studio, 2013), the recommendation results are not convincing due to the limitation of dealing with a large volume of clothing data with real-time feedback by human agent (stylists/fashion experts). Furthermore, one thing that customers doubt about is those professionals may have 
their intension of promoting sales while making suggestions, especially from bloggers and celebrities recommendations as indicated in a story about how style bloggers earn sale commissions (Holmes, 2015).

Smart retailers are seeking novel solutions of combining automatic machine recommendations with higher trustworthy word-of-mouth recommendations. There is an example in existing market, called Style Seek which was born on 2011 created by MIT graduates (Styleseek, 2015). Its creators call their sites 'Pandora for ecommerce products' which predicts users' shopping preferences without relying on social media feeds, or tracking users' previous behaviours. Instead, it introduced a 'style game' in which the user spends 20 seconds to pick up 9 images referring to his/her lifestyle to define a user's personal style called 'Style DNA'. Each image is selected from 9 different styles of cars, male magazines, hobbies, music types, movies, interiors, watches and wines. StyleSeek have reached 50,000 registered users, \$ 1 million in transaction and engaged with 200 apparel retailers. One of leading fashion magazines GQ criticized that applying analytics to a 9-step profiling quiz doesn't work out personal styles which are filled with intuition, experience and an eye for style (Ferguson, 2013). Regarding to the web traffic, the up to date analysis from the SimilarWeb showed that Style Seek kept $2 \mathrm{~K}$ visits in January 2016 (SimilarWeb, 2016). It is not a huge amount, but still acceptable to compare with Boutiques.com by Google which is a similar recommendation startup launched in 2011, then closed in 2012 duo to less traffic according to similarweb data (Widhadh, 2012).

In summary, many stories reflect that product recommendation is a booming, creative, beneficial, but unstable market. Automatic recommendation technologies have been widespread rapidly among various retailers though they are still looking for the more in-depth algorithms to deliver better results in order to earn more trusts from their users. In apparel categories, Word-of-mouth recommendations, such as online stylists and social shopping, occupy the largest markets as higher trustworthy suggestions. But it is apparently less productive facing the huge online markets and data. Many startups innovated with advanced systems engaging with fashion professionals and peers. Their web traffics are much smaller, which is still a work in progress. So far, there are no leading retailers or technology developers which have brought significant success in developing apparel personalized recommendation models. Following sections will review apparel recommendation systems through academic research.

\section{Literature review method}

A literature review has been conducted. The resources of literatures are from journal papers, conference proceedings, $\mathrm{PhD} /$ Masters theses, books, fashion magazines, fashion web/blogs, and reports. Online Database of Scopus, SCIRUS, ScienceDirect, Web of Science, NORA and DAAI are used as database sources. The key words used to search articles are organised in three descriptor groups with rules listed below. In order to make a logical search, Boolean operators 'AND' or 'OR' are adopted to manage searching rules. $R_{1}, R_{2}$ and $R_{3}$ represent the three descriptor groups respectively with the rule of ' $O R$ '. $R$ is the sum of $R_{1}$ and $R_{2}$, or $R_{I}$ and $R_{2}$ and $R_{3}$ with rule 'AND'. For instance, several words combinations, such as 'fashion' with 'coordination', 'style' with 'recommendation' and 'expert system' have been examined.

$\checkmark \quad \mathrm{R}_{1}=$ keywords $\in$ (garments OR apparel OR cloth* OR attire OR outfit OR fashion OR style OR dress*)

$\checkmark \quad \mathrm{R}_{2}=$ keywords $\in$ (recommend* OR advisor OR advice OR design OR coordination OR matching OR Mix-and-Match OR searching OR retrieval OR evaluation OR preference OR prediction OR forecasting)

$\checkmark \quad \mathrm{R}_{3}=$ keywords $\in$ (Artificial Intelligence OR Expert System OR Neural Networks OR Image Processing OR Image Retrieval OR Image Feature extraction)

$\checkmark \quad \mathrm{R}=$ keywords $\in\left(\mathrm{R}_{1}\right.$ AND $\mathrm{R}_{2}, \mathrm{R}_{1}$ AND $\mathrm{R}_{2}$ AND $\left.\mathrm{R}_{3}\right)$

'*'refer to truncation searching, e.g. Recommend*=recommend/recommending/recommendation/recommender

As a final retrieval result, a total number of 130 literatures from 7 categories of resources are found and classified (see Table 2). After receiving this dataset, an initial data analysis is performed in order to identify the research trend and where the most useful resources are. A number of 97 literatures are from journal and conference publications which considered as the most valuable sources from an academic point of view. Books 
give systematic and theoretical knowledge of fashion, style and dressing. For instance, some authors introduced how to be well-dressed with style, colour, fabric, gentleman look, occasion, culture and society (Lenius, 1998, Hix, 1981, Simple and Hochswender, 1998, Roetzel and Beer, 2009, Eicher and Evenson, 2015). Fashion magazines, websites and blogs are also reviewed as considering the impacts of fashion on apparel recommendation system. Magazines include GQ, Esquire, Another man, Menswear Style, CLIENT, Man of a kind, and Menswear Buyer. Mackie et al. (2014) reviewed the magazine of Another Man as a visual archive. Fashion blogs and websites are from Tailor made London, The fine young gentleman, A suitable Wardrobe, Mensstylepro, Teaching mens fashion, Real men real style, I am alpham, Articles of style, and Style girlfriend. The style expertise posted by fashion bloggers could contribute to formulate knowledge-based recommendation model.

\begin{tabular}{lr} 
Distribution of Resources & 65 \\
\hline Journal Papers & 32 \\
Conference Papers & 6 \\
PhD/Masters Theses & 8 \\
Books & 7 \\
Fashion Magazines & 9 \\
Fashion Web/Blogs & 3 \\
Reports & 130 \\
Total &
\end{tabular}

In academic publications, figure 1 and table 3 analysed the distribution of academic articles by year and journals respectively. Year distribution shows that research articles increased dramatically since 2012, especially, computer intelligence related international conferences have attracted 21 out of 32 conference papers. In addition, the journal distribution demonstrates a wide scope of research fields in clothing and textile, fashion, marketing, design, economics, computer-aided design, computer graphics, artificial intelligence, information engineering, and machine learning. The top 3 journals having related publications are international journal of clothing science and technology, international journal of fashion design, technology and education and journal of expert system with applications, with retrieval results of 22, 5 and 4 papers respectively. Following up this initial data analysis, it is extracted from each paper in terms of research questions and methods, contributions and future researches. Then the detailed analysis will be carried out against each term. The research findings from the analysis are detailed in the following sections.

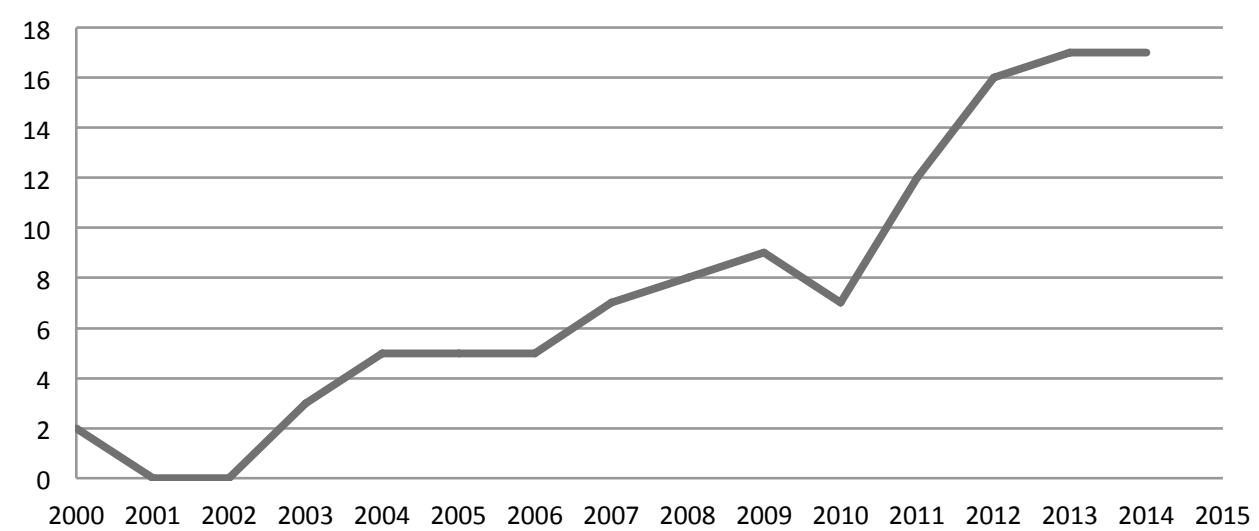

Figure 1 Distribution of articles by year

Distribution of Resource- Journals

\begin{tabular}{lr}
\hline -International Journal of clothing science and technology & 22 \\
-Clothing and textile research journal & 2 \\
\hline
\end{tabular}




\begin{tabular}{ll}
\hline -Journal of fashion marketing and management & 3 \\
-International journal of fashion design, technology and education & 5 \\
-Textile research journal & 2 \\
-Journal of textile and apparel, technology and management & 2 \\
-Journal of The Textile Institute & 1 \\
-Pattern Recognition and Image Analysis & 1 \\
- Journal of Consumer Research & 1 \\
-Communication of the Association for Information Systems & 1 \\
-Automation Science and Engineering & 1 \\
-Electronics and Communications in Japan & 1 \\
-Computer Aided Design & 2 \\
-Body Image & 1 \\
-Fashion Theory & 2 \\
-Design studies & 1 \\
-International Journal of production Ergonomics & 1 \\
-Computers in Industry & 2 \\
-Artificial Intelligence & 1 \\
-Computers \& Graphics & 1 \\
-Computer graphics and applications & 1 \\
-Graphics Recognition & 1 \\
-Expert system with applications & 1 \\
-Journal of Information Science and Engineering & 1 \\
-Journal of Applied Science and Engineering & 1 \\
-Mathematical Problems in Engineering & 1 \\
-Research Journal of Applied Sciences, Engineering and Technology & 1 \\
-International Journal of Advanced Operations Management & 1 \\
\hline -Advanced Materials Research & 1 \\
\hline Tole 3 Distributions of ResourCe-Journals & 1 \\
\hline
\end{tabular}

Table 3 Distributions of Resource-Journals

From the 97 research papers appeared in journals and conferences, in order to investigate the research focuses, Tagcrowd approach was applied to extract keywords distributions from all the articles. The keywords of recommend*, cloth*, garment, apparel were excluded. The rest 261 words or word groups were collected and analysed. Figure 2 illustrates the top 50 words with the highest frequency. The result shows that the top-ranking keywords are design, fashion, system, genetic algorithm, modelling, style, coordination, decision, e-commerce, knowledge, fuzzy and neural networks. Intelligent methods occupied a significant proportion in apparel recommendation system research. Keywords regarding to apparel styles and users rarely appeared. Only colour and style were emphasised. It shows fairly insufficient research attentions in terms of user concerns, such as how body shapes could impact apparel styling and selections. 


\section{acquisition analytical-hierarchy-process classification cognitive colour coordination decision design e- commerce element evaluation expert fashion female filtering fuzzy garment genetic-algorithm genres hci image industry information interface kansei knowledge making management mass-customization methodologies modelling network neural-networks online ontology perception product reasoning recognition research sensory shopping similarity social statistics strategic style SyStem user visual}

Figure 2 Distributions of articles by Keywords

\section{Research findings}

\subsection{Research Classifications of Apparel Systems}

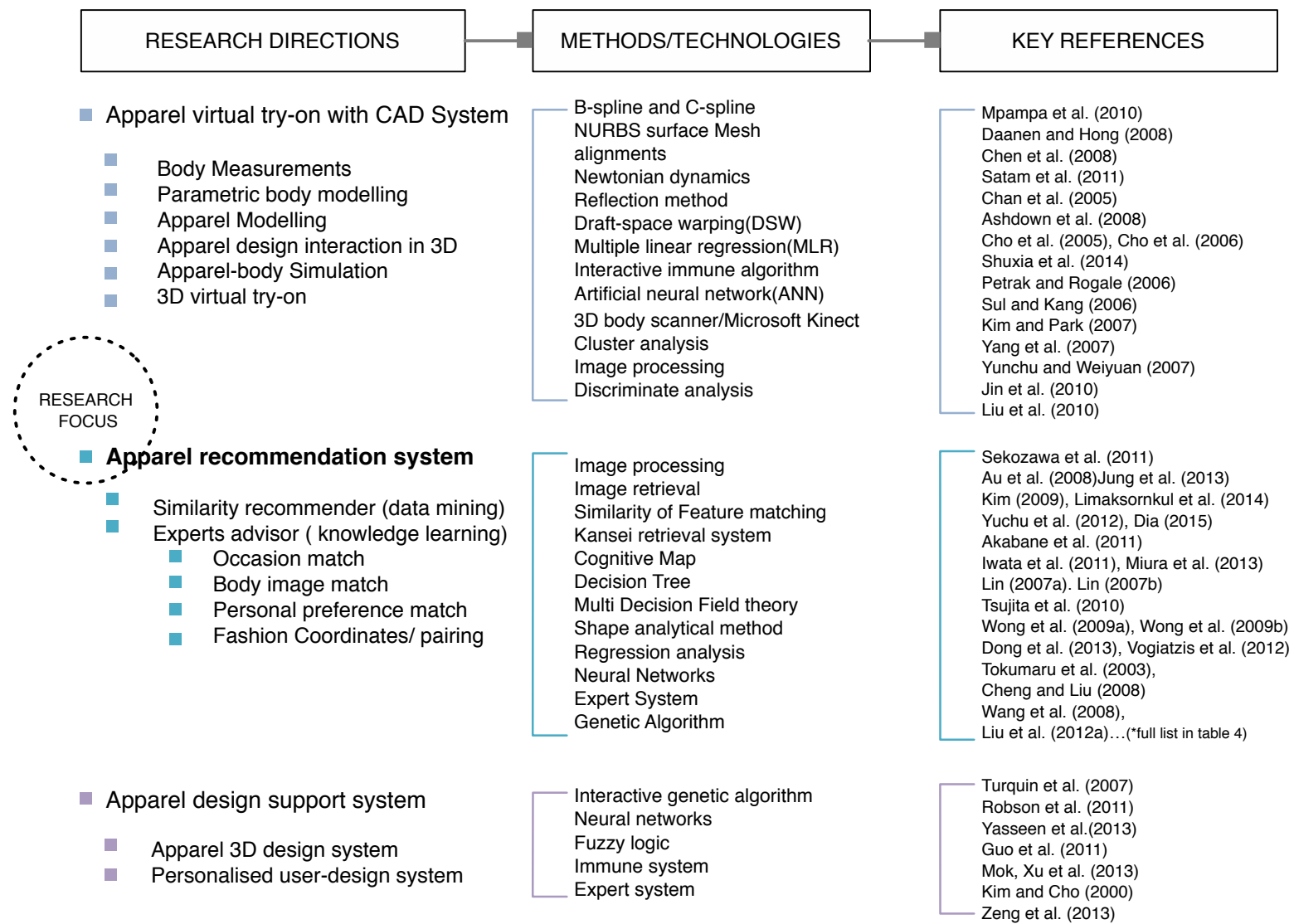

Figure 3 Classification of apparel systems research on apparel retailing

Figure 3 shows the classification of related apparel retailing systems researches. The cloth models associated with the identified researches are listed in Table 4, they are from All womenswear, All menswear, Womenswear and Menswear, Men's Suit and Women's Jacket. The main cloth model was found from All womenswear with 17 related studies. After that, cloth model in both Womenswear and Menswear also attracted research attentions accordingly, and 7 studies were associated to this model. As we can see, research interests in womenswear were much more than menswear. In terms of clothing category, all categories of either womenswear or menswear have been taken into account in the majority models, only a few studies put their focuses on separate category of men's suit or women's jacket. 


\begin{tabular}{ll} 
Cloth models & Related research \\
\hline All womenswear & (Liu et al., 2012a, Masuko and Hayashi, 2013, Dai, 2015, Lin, 2007b, Iwata et al., 2011, \\
& Akabane et al., 2011, Lin, 2007a, Jagadeesh et al., 2014, Vuruskan et al., 2015, Dong et al., \\
& 2013, Liu et al., 2012b, Tsujita et al., 2010, Cheng and Liu, 2008, Yu-Chu et al., 2012, Tu and \\
& Dong, 2010, Sekozawa et al., 2011, Tokumaru et al., 2003) \\
\hline All menswear & (Kim, 2009, Nagao et al., 2008, Shen et al., 2007, Kim et al., 2013) \\
\hline Womenswear and Menswear & (Miura et al., 2013, Dai, 2011, Kalantidis et al., 2013, Limaksornkul et al., 2014, Yamada and \\
\hline Men's suit & Takami, 2012, Zhang et al., 2008, Vogiatzis et al., 2012) \\
\hline Women's Jacket & (Hong Lu, 2013, Zeng et al., 2013) \\
\hline
\end{tabular}

Table 4 Distributions of Cloth models associated with related research

Apparel virtual try-on with CAD system

One of advanced apparel systems, virtual try-on, has received significant research attentions based on 3D garment CAD techniques with topics from body measurements and modelling to apparel modelling, design and simulation (Mpampa et al., 2010, Daanen and Hong, 2008, Chen et al., 2008, Satam et al., 2011). Instead of manual tap measurements, 3D body scan techniques (Chan et al., 2005) are applied for automatic body measurements and size extractions, such as $[\text { TC }]^{2}$ Body Scanner $\left(\mathrm{TC}^{2}, 2011\right)$ and 3D-A-PORTER Body Scanner (3D-A-PORTER, 2012). Parametric body mannequin modelling is further conducted according to 3D scan data (Ashdown et al., 2008, Cho et al., 2005, Cho et al., 2006, Shuxia et al., 2014). In terms of apparel modelling, alterations and simulations, research has drawn on clothes draping, material dynamics, and body animations (Petrak and Rogale, 2006, Sul and Kang, 2006, Kim and Park, 2007, Yang et al., 2007, Yunchu and Weiyuan, 2007, Jin et al., 2010, Liu et al., 2010). In a word, current research has achieved virtually trying on clothes. Nevertheless, the accuracy of simulation results needs to be further examined in practice. A virtual try-on software are introduced by MIRALab, some visual stores are also developed, while, as a report said (e-Tailor, 2002), such a system needs more life-like 3D body and dressing results in order to satisfy customers.

\section{Apparel design support system}

Conducting creative design is a challenge in existing 3D garment CAD systems, sketch-based 3D garment design as a solution has been discussed (Turquin et al., 2007, Robson et al., 2011, Yasseen et al., 2013). In order to automatically generate apparel designs, Guo et al. (2011) have dedicated to develop artificial intelligence based CAD systems via neural networks, genetic algorithm, fuzzy logic, immune system and expert system. Apart from this, some personalised style design systems (Mok et al., 2013, Kim and Cho, 2000, Zeng et al., 2013) allow users to create their own style. A customised fashion design system (Mok et al., 2013) could provide sketch based style design model for users to design their personalised style looks with a user friendly interface. Interactive Genetic Algorithm has been applied in his model with three sets (levels) of parameters: silhouette, key style elements, and design details.

\section{Apparel recommendation system}

Personalised design support systems customize products by wearer themselves to meet their desires. However, because the wearers as non-professional users are equipped with less individual fashion knowledge and taste, it is hard to make decisions in style selections from either personalised designs or ready-to-wear clothes without professional skills, such as fashion coordination and occasion needs. Apparel recommendation systems with personalised styling advices and smart recommendation technologies have been designed to fill this gap. In this area, research topics are divided into two branches, namely similarity recommender study and expert advisor study. Image processing, sensory engineering, mathematical algorithms and artificial intelligence methods have been extensively adopted to support above systems. In this paper, apparel recommendation systems will be discussed in detail in the following sections.

\subsection{Developments of Apparel Recommendation Systems}




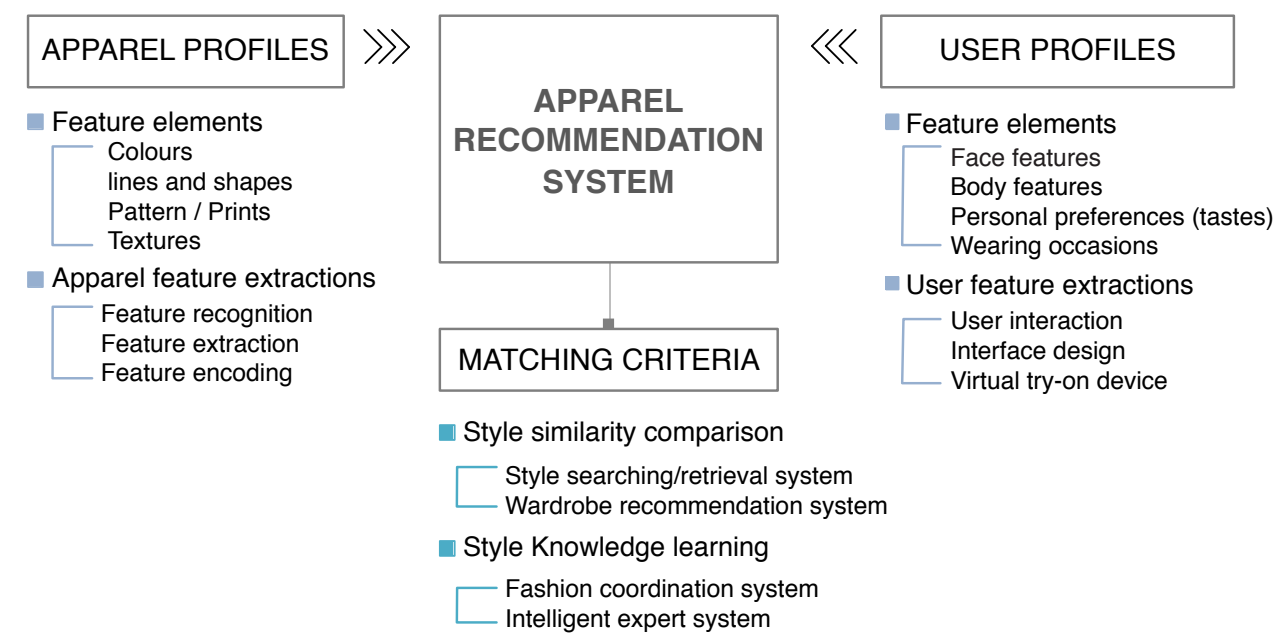

Figure 4 apparel recommendation system structure

Apparel recommendation systems refer to feature matching between apparel and users under certain matching criteria. As shown in figure 4, from the apparel side, current research addresses apparel features from its formulation of colours, lines and shapes, pattern/prints and textures. The descriptive methods of above features were studied through the process of feature recognition, extraction and encoding. On the other side, user features are recognised as facial features, body features, personal preference (taste) and wearing occasions. A welldescribed user profile could distinguish a more personalised recommendation system from general systems. The key research challenges are from the matching criteria.

We classified the recommendation systems into four categories according to their matching criteria (or models), including style searching/retrieval, wardrobe recommendation, fashion coordination and intelligent expert systems. The former two kinds of models calculate the similarity of style form features between new clothes and query clothes items from purchase, liked, or wearing history. Those clothing from same category are compared, e.g. to recommend a similar suit jacket from what suit jackets you have bought/liked before. Instead of similarity computations, the latter two models integrate style knowledge into matching style form and expressional features from both upper and bottom clothing categories, e.g. to pair a suit jacket with a shirt creating a modern look for business occasions. This requires fashion and clothing knowledge, hence, intelligent knowledge learning and knowledge acquisition are introduced to construct system model. As shown in Table 5, the corresponding research directions, methods and techniques are analysed and clustered with references.

\begin{tabular}{|c|c|c|c|c|}
\hline System types & Apparel profiles & User profiles & Computation Methods & References \\
\hline $\begin{array}{l}\text { Clothes searching/ } \\
\text { retrieval systems }\end{array}$ & Style form & Purchase/browse history & $\begin{array}{l}\text { Collaborative Filtering } \\
\text { Feature similarity analysis } \\
\text { Analytical Hierarchy Process } \\
\text { Interactive Evolutionary } \\
\text { Algorithm } \\
\text { Entropy method }\end{array}$ & $\begin{array}{l}\text { (Vogiatzis et al., 2012, Au et } \\
\text { al., 2008, Jung et al., 2013, } \\
\text { Jagadeesh et al., 2014, Liu } \\
\text { et al., 2012b, Xiao-song et } \\
\text { al., 2014, Kalantidis et al., } \\
\text { 2013, Hidayati et al., 2012, } \\
\text { Zhang et al., 2008, } \\
\text { Sekozawa et al., 2011) }\end{array}$ \\
\hline $\begin{array}{l}\text { Wardrobe } \\
\text { recommendation } \\
\text { systems/devices }\end{array}$ & Style form & Wardrobe usage history & $\begin{array}{l}\text { Past statistics learning } \\
\text { Interface design } \\
\text { Bayesian Network } \\
\text { RFID } \\
\text { Social network }\end{array}$ & $\begin{array}{l}\text { (Limaksornkul et al., 2014, } \\
\text { Dumeljic et al., 2014, Kim, } \\
\text { 2009, Yu-Chu et al., 2012, } \\
\text { Yamada and Takami, 2012, } \\
\text { Nagao et al., 2008, Yan et } \\
\text { al., 2011a) }\end{array}$ \\
\hline $\begin{array}{l}\text { Fashion Coordination } \\
\text { (Clothes pairing) } \\
\text { systems }\end{array}$ & Style genre & $\begin{array}{l}\text { User preferences } \\
\text { (tastes) }\end{array}$ & $\begin{array}{l}\text { Image recognition } \\
\text { Probabilistic topic model } \\
\text { Genetic Algorithm } \\
\text { Artificial Neural networks }\end{array}$ & $\begin{array}{l}\text { (Masuko and Hayashi, 2013, } \\
\text { Iwata et al., 2011, Lin, } \\
\text { 2007b, Lin, 2007a, Vuruskan } \\
\text { et al., 2015, Dai, 2015, } \\
\text { Miura et al., 2013, Na and } \\
\text { Agnhage, 2013, Akabane et } \\
\text { al., 2011, Tsujita et al., } \\
\text { 2010) }\end{array}$ \\
\hline Intelligent & Style form & User preferences & Expert System & (Kim et al., 2013, Tu and \\
\hline
\end{tabular}




\begin{tabular}{|c|c|c|c|c|}
\hline $\begin{array}{l}\text { recommendation } \\
\text { systems }\end{array}$ & Style genre & $\begin{array}{l}\text { User Body features } \\
\text { Wearing occasions }\end{array}$ & $\begin{array}{l}\text { Fashion Ontology } \\
\text { Positive rule reasoning } \\
\text { Common sense reasoning } \\
\text { Decision Tree } \\
\text { Analytical Hierarchy Process } \\
\text { Sensory Engineering } \\
\text { Fuzzy Mathematics } \\
\text { Genetic Algorithm } \\
\text { Neural Networks } \\
\text { Support Vector Machine }\end{array}$ & $\begin{array}{l}\text { Dong, 2010, Vogiatzis et al., } \\
\text { 2012, Liu et al., 2012a, Lu et } \\
\text { al., 2013, Dong et al., 2013, } \\
\text { Dai, 2011, Hong Lu, 2013, } \\
\text { Yinggang et al., 2007, Zeng } \\
\text { et al., 2013, Wong et al., } \\
\text { 2009b, Wong et al., 2009a, } \\
\text { Li and Li, 2012, Cheng and } \\
\text { Liu, 2008, Shen et al., 2007, } \\
\text { Liu et al., 2009, Tokumaru } \\
\text { et al., 2003, Wang et al., } \\
\text { 2008) }\end{array}$ \\
\hline
\end{tabular}

Table 5 Systems classification

\section{Clothes searching/retrieval systems}

Clothes searching/retrieval systems were formulated by clustering clothes group through feature similarity and correlation analysis based on individual historical data, such as previous sales, clothes purchase records, eye movement records and item click rate. A one-to-one Recommendation system (Sekozawa et al., 2011) was designed with the key function of suggesting garments to suit the user's tastes using analytical hierarchy process (AHP), meanwhile, it also provides secondary purchase item recommendation based on other consumers' purchase data with the same tastes using market basket analysis. Au et al. (2008) proposed a fashion retail forecasting system with evolutionary neural networks based on two years' sales data. Results showed that the proposed ENN model could assist fashion retailers to make decision in sales forecasting. Jung et al. (2013) proposed a recommendation system with eye movement analysis which human preference can be measured by tracking eye gaze information including fixation count and length. They indicated that it is difficult to express the human aesthetics or preference in the form of mathematical expression due to individual subjectivity and defer of judging from subject to subject, and it may be even inconsistent with the same items judgements when compared with other designs. Interactive Evolutionary Algorithms (IEAs) have been applied for predicting the user's style preferences, which optimizes personal preference in the course of evolution by directly interacting with the user instead of predefined functions. To tackle the subjectivity and inconsistence during an interactive items scoring process, eye tracker method has been employed to reduce errors of preference judgements.

\section{Wardrobe recommendation systems}

Besides of purchase, liked or browse data, wardrobe recommendation systems search similar style forms using wardrobe usage history. It has been mostly applied for daily recommendation in conjunction with weather and temperature conditions. Some recommendation devices are also developed, such as, a ubiquitous fashion coordination mirror (Kim, 2009) was designed with a friendly user interface to pair clothes based on time, occasion, place and daily schedule. Limaksornkul et al. (2014) also suggested learning from past statistics to build up a smart closet system which could suggest appropriate clothes for current conditions of weather and special occasions. Another personalised clothing system recommending from the user's wardrobe was developed based on a Modified Bayesian Network (Yu-Chu et al., 2012) with the feature of reflecting items usage history.

\section{Fashion coordination systems}

Above two types of systems deal with style form features, the searching results highly depended on the computation algorithms of form feature similarities. While, fashion coordination aims to match different category clothes according to styling knowledge in terms of the meanings and expressions behind the style forms. Some researchers adopted style genre to represent the matching rules and knowledge of fashion coordination. For instance, 12 fashion categories of Avant-grade, elegant, folk leisurely et al. were employed to measure the style combinations (Dai, 2015). It was also measured through impression values based on Kansei words, such as boyish vs. feminine (Akabane et al., 2011). Another approach was to choose well-designed style combinations from fashion magazine or websites, using image detection technology to extract similar clothes style and learn its combinations (Iwata et al., 2011, Miura et al., 2013). Style coordination knowledge was also learned by combining style genres and intelligent methods, such as genetic algorithm (GA). An intelligent 
apparel system (Lin, 2007b, Lin, 2007a) could recommend design scheme through a searching mechanism based on GA and a classifier by an artificial neural network (ANN). In addition, style suggestions from friends were also utilised to receive fashion coordination through internet and common SNS site (Tsujita et al., 2010).

\section{Intelligent recommendation systems}

Intelligent recommendation systems took more features of apparel and user profiles into consideration in terms of users physical, wearing contextual, apparel form and genre features. In order to understand the interrelationships between the apparel and user, expert recommendation systems were introduced in accordance with domain expertise knowledge of style matching criteria through intelligent algorithms. For instance, an apparel expert system integrated knowledge of fashion designers, with T-S fuzzy neural network method to learn the expertise of attribute evaluation. It created an expert knowledge database from symbolic inputs to linguistic outputs through an inference engine (Wong et al., 2009a, Wong et al., 2009b). Based on expert rules, a study proposed an intelligent apparel recommendation expert system by positive rule reasoning mechanism (Dong et al., 2013). Apart from this, Vogiatzis et al. (2012) combined expert's knowledge with the customer's purchase data in order to extract the matching rules by Servive Fashion Ontology (SFO) method which provided a structured and unified vocabulary to represent human, fashion and manufacturing concepts.

Experts' knowledge was kind of YES or NO rules, some of other systems aimed to understand deeply of the apparel and user interplays. It regards to consumers' perceptions and understandings of apparel features in an aesthetical and emotional way, as well as some common rules of dressing agreed by public, such as occasion dress. These have been integrated in developing clothing search systems which aim to retrieve clothes based on people's understandings of style features. Virtual Style Project (Tokumaru et al., 2003), an adaptable clothing search system, was built to evaluate colour image sensations with the user's subjectivity on clothes impressions by Interactive Genetic Algorithms. In an ALCOVE model, a sensational cognition model was employed in an intelligent clothes search system for classifying apparel according to impression. Warmth, softness, and vivaciousness are the sensation factors of the impression space, which are used to measure impression effects on all apparel essentials including colour, outline, print type, and texture (Cheng and Liu, 2008). Sensory research on clothes style aimed to establish the relationship between design elements and the user's impression using semantic space and product elements space based on sensory engineering knowledge (Wang et al., 2008).

\section{A case study}

Magic closet is an intelligent recommendation system as they used Artificial Intelligence method to do system modelling. It is an occasion-oriented apparel recommendation developed by Liu et al. (2012a). In line with table 4 of system analyses, here we analyse magic closet through user profiles, apparel profiles and computation methods. In user profiles, wearing occasion is the only factor accounted without considering body features and preferences. To the apparel profiles, this system defined apparel attributes as colour, pattern, material, collar, sleeve and length, which all belong to apparel formal features. Magic closet adopted two criterions of wear properly and wear aesthetically as matching criteria. The system was modelled accordingly based on the two criterions. Specifically, during the data collection stage, a large dataset called "What-to-Wear" was conducted including 24,417 clothing. They sent a very large number of clothing into Amazon Mechanic Turk, a crowdsourcing tool, to complete the annotations of apparel attributes and occasion. The advantages of crowdsourcing approach are clear to see in this case. Regarding to computation methods, such a large set of clothing with annotations of occasions and attributes were learned through Latent Support Vector Machine methods in order to extract the underlying rules of matching apparel with occasions. This system has preformed positively in clothing suggestion and pairing based on occasions. In the future, it will tend to be more personalized by engaging with specific user profiles and apparels from user's collections.

\subsection{System modelling approaches comparisons}

Many modelling methods were adopted among above four types of systems. Both realistic and superficial approaches were seen through data collections and analyses of the modelling process. In users data collections, data mining through users' historical behaviours is on surface level of knowing customer personal information 
and predicting product preferences. In comparison, crowdsourcing using public intelligence are relatively trustworthy as it could collect data from certain groups that the users would trust more. Collecting apparel data, automatic image recognition methods showed great value in terms of apparel features extractions. And then, features descriptions and encoding could go deeper by knowing how customers perceive apparel features. Sensory engineering played a vital role in connecting apparel features with users' feelings. As for data analysis methods, collaborative filtering functioned such as "who bought this also viewed" did not work well without knowing individual customers purchase intensions, e.g. looking for something for others rather than themself. By contrast, machine learning predicted preferences according to reliable primary data from expert knowledge or peer opinions rather than web data received indirectly. For instance, SVM approach in the case study has shown its advantages of analysing complex inter-relationships between users and apparel features, as well as occasions.

In summary, style searching/retrieval models coped with feature matching between new products and the user purchased/liked products, without concerns of the user's personal information, e.g. body shape, and occasions. Wardrobe recommendation systems or devices considered the user interface and interactions, but also showed limitations in terms of tracking wardrobe usage history. The criteria of above two systems are to match up similar styles based on style form features. In contrast, a fashion coordination system pairs completely different style categories, which is hardly measured by feature similarity computations. Therefore, fashion coordination knowledge was employed to match styles from their expressional features and semantic meanings. While an intelligent system takes experts' knowledge into account to capture clothing professionals' knowledge on body and occasion matching between products and individual consumers. Some of other smart systems added more theories into capturing matching rules, such as product perceptions and emotions. Beyond above, more and more design theories, such as product aesthetics should also be able to guide recommendation model. Because, it explains product features from the knowledge of design aesthetic principles which explain design elements organisation, e.g. rhythm, balance, proportion and emphasis (Fiore, 2010), as well as Gestalt psychology which describes the arrangements of design units' cohesion.

\subsection{Research gaps analyses}

\section{The research gap in apparel profiles}

In apparel recommendation, apparel profiles refer to style design elements of colours, lines and shapes, patterns, prints, and textures, which are utilized to describe apparel appearance features. It is found that apparel lines and shapes representing the style structure have been addressed in 26 articles as the most important feature. Some studies addressed this feature in diagrams as the only attribute of apparel (Zeng et al., 2013, $\mathrm{Li}$ and $\mathrm{Li}, 2012$, Mok et al., 2013). Colour also occupied a significant proportion due to the correlations with the user's colour images, such as skin tone, hair colour, and eye colour. Vogiatzis et al. (2012) classified above colours into groups of four seasons namely spring, summer, autumn, and winter to describe the user's colour image and analyse the impacts of style colour or colour combinations. Among these essential features, style surface features of pattern, prints and texture were seldom mentioned in existing research, thus there is still an open research question on how to effectively utilise them in a recommendation system.

Regarding to the descriptions of each elements, both manual and automatic approaches have been discussed. Manually, research on men's overcoats described style feature as Chester, Duffle, Ulster, Balmacaan, and Trench based on style name (Zeng et al., 2013). Apparel lines and shapes were also classified based on style components of silhouette, collar, shoulder, waist, sleeve, hem, pocket and front by Li and Li (2012). Liu et al. (2012a) introduced six attributes of colour, pattern, material, collar, sleeve and length with their values indicated. In automatic approaches, many computer vision algorithms are applied for apparel features recognition, extraction, and encoding (Tu and Dong, 2010, Kim et al., 2013, Cheng and Liu, 2008, Zhang et al., 2008). Tu and Dong (2010) introduced Video images in a web-based fashion multimedia mining model. Apparel colours, contours, and skin colours were extracted from fashion models in video scene by a two-step processing with a soft matting algorithm and optical flow method in localisation of foreground and background, and refined contour extraction. Linear Support Vector Machines and Decision Stumps methods were employed for feature 
extraction of sleeve length, collar, placket, style colour, skin colour, pattern and prints from a camera sensor (Zhang et al., 2008). Style colour, texture and structure features are used to build an automatic description model of clothes image by image segmentation and a region-based interpretation (Borras et al., 2003). For colour feature extraction, mean shift image segmentation algorithm and K-means clustering algorithm were applied by Kim et al. (2013). Cheng and Liu (2008) introduced warmth, vivaciousness, and softness to describe the combined features of colour, prints, outlines and fabric.

It was clear that various methods have been discussed in features descriptions. Facing a large volume of online data, apparel features automatic extractions have been introduced instead of tedious manual inputs, with computer vision technologies, such as image segmentation and interpretation. Among the design elements, colours, patterns and prints have shown the abilities of automatic description. Whereas, lines with complexity still need further research. The proportion and symmetry of lines as descriptors can be used to feature description and similarity analysis. In addition, both ways calculate apparel features towards the nature attribute of apparel, such as name and components. It is insufficient to represent and distinguish an article of clothing from others without the concerns of its design and emotional attributes. Design attributes indicate the design organizations and placements of colours, styles, patterns, prints and materials. For instance, in Liu et al. (2012b)'s model, besides of colour code and name, the percentage, number of colours, colour scheme, adjacent colour and contrast colour were also encoded to represent apparel colours. Emotional attributes reflect the meanings behind the apparel form, e.g. formal, young, elegant, classic, renascent, et al. Generally, this attribute bridges the connections between apparel and user profiles by understanding how users perceive the design of apparel forms through semantic words.

\section{The research gap in user profiles}

User profiles were less mentioned, comparing with apparel profiles. User studies aim to meet individual demands therefore contributing to customise recommendation systems. Many proposed systems, such as fashion coordination and clothes searching system, did not take users body images into consideration. This study summarized user profiles incorporated with personal preferences (tastes), physical features, and wearing contextual conditions. Personal style preferences (or tastes) are very individual due to the differentiations of demographic profiles and fashion sensitivity. Most of current recommendation technologies are focusing on personal preferences matching. No matter what the user's profiles or fashion tastes are, it receives the user's preferences indirectly from their purchase or like/dislike data. Instead, some studies found ways to analyse above features. In an interaction recommender model (Tu and Dong, 2010), the relationship between leading fashion trend and personal character was input with interactive items selection. The fashion trends were also integrated into an expert system based on fashion professionals' knowledge (Wong et al., 2009b).

Some articles focused on the relations between physical features and apparel styles, including body shape, height, weight, facial features and skin colour et al.(Jones and Giddings, 2010, Grogan et al., 2013, Park et al., 2009, Kim and Damhorst, 2010, Lee et al., 2007). Grogan et al. (2013), found that people use clothes to increase body confidence, camouflage and try to attain a slender hourglass look. Body shape was the main element addressed in current systems. To match up four non-standard female body shapes of $\mathrm{V}, \mathrm{A}, \mathrm{H}$ and $\mathrm{O}$ with clothing shapes, an intelligent fashion style selection system was studied based on genetic search and neural classification methods (Vuruskan et al., 2015). Another intelligent recommender system was designed to support fashion design in matching the user's body shape features with a desired fashion theme of apparel items according to the consumer's perception and emotion (Zeng et al., 2013). Furthermore, the user's skin colour was considered in a proposed intelligent personalised fashion recommendation system which predicts the user's preferences of clothes style and colour through an interactive test of samples selection process with a developed hierarchical fashion multimedia retrieval model (Tu and Dong, 2010).

Apart from the concerns of users and apparel, wearing occasions also plays a vital role in contributing apparelwearing success. Occasions have been mentioned in many studies (Yu-Chu et al., 2012, Wong et al., 2009b, Wong et al., 2009a, Vogiatzis et al., 2012, Cheng and Liu, 2008). A scenario-oriented recommendation system was introduced to match apparel with daily scenarios by a semantic network based on common sense reasoning 
technology-Open Mind Common Sense (OMCS), which contains over 800,000 English sentences about common sense (Shen et al., 2007). An occasion-oriented system, magic closet, was proposed to recommend clothes for six occasions of travel, funeral, wedding, dating, conference and sports based on two criterions of wear properly and wear aesthetically (Liu et al., 2012a). Few daily-based recommendation systems also addressed occasion issues, incorporating with the weather, temperature, place and social environments (Yamada and Takami, 2012, Nagao et al., 2008, Goh et al., 2011, Yan et al., 2011b).

In a word, even though research has paid less attention to user profile, it was still seen that many elements, such as personal preferences, body shapes and occasions were concerned in current studies. However, how to extract the elements as an open question was rarely mentioned in the above research. In order to obtain user information, the research into user interaction and interface design requires more attentions. Current virtual tryon technologies with smart devices (e.g. virtual dressing room, Visual mirrors) have the advantages of body information extraction and display. In order to automatically extract both apparel style and the wearer's physical features, integrating virtual try-on technology into user interaction of apparel recommendation system can be a viable research direction.

\section{Proposed new research}

Heretofore, the focal point of existing research is the matching model computations of recommendation systems with various intelligent algorithms. Even though, according to the review of "Artificial Intelligence application in the apparel industry" (Guo et al., 2011), AI-based methods have been widely applied for apparel manufacture, while, researches on fashion coordination and recommendation of apparel retailing only occupied $4.2 \%$ of publication by 2010. We found that computer intelligence methods have raised significant attentions in apparel recommendation research from 2011 to 2015. Regarding to intelligent methods, Neural Networks, have been widely incorporated into knowledge learning. It simulates the decision making process of human brain with main functions of classification and forecasting, with the advantage of learning all style essentials interplays which are hardly described by a specific mathematical function. Besides neural networks, recently, Liu et al. (2012a) proposed a latent Support Vector Machine (SVM) based recommendation model for occasion-oriented matching and pairing.

It is seen that many mathematical methods have been tested in constructing recommendation model which is matching apparel profiles with user profiles. Each method has different ways to extract and encode apparel and user features. This study selected 30 well-developed systems to investigate the research implementations regarding to apparel and user profiles. It was found (Table 6) that significant attentions were paid on apparel elements, with $63 \%$ of the developed systems addressed related issues. Among these, the elements of line \& shape and colour showed the best interests in these researches, with 26 and 23 articles respectively. In contrast, research rarely mentioned the feature elements from the user side in terms of facial features (4), body features (6), style preferences (5) and wearing occasions (9).

\begin{tabular}{llccc}
\hline & Feature elements & Number of Publications & Percentage $\%$ & Total \% \\
\hline \multirow{2}{*}{ Apparel } & Line and Shape & 26 & $87 \%$ & \\
& Colour & 23 & $77 \%$ & \\
& Pattern and Prints & 10 & $33 \%$ & \\
& Texture & 10 & $33 \%$ & $65 \%$ \\
\multirow{4}{*}{ User } & Facial features & 4 & $13 \%$ & \\
& Body features & 6 & $20 \%$ & \\
& Style preferences (tastes) & 5 & $17 \%$ & \\
& Wearing occasions & 9 & $30 \%$ & $35 \%$ \\
\hline
\end{tabular}

Table 6 The apparel and user profiles research distributions

Therefore, this study proposed a comprehensive parameter set describing apparel and user profiles in apparel recommendation system. Design knowledge was introduced in exploring apparel profile features in order to encode an article of clothing distinguished with others. As shown in table 7, suit/blazers in menswear category was selected as learning sample. The nature features of apparel lines and shapes, colours, patterns, prints and 
textures characterize the components of apparel and the specialities of each component. Design organizations are able to explain the combination law of how all of the elements are combined together to form an article of clothing. These parameters consist of proportion, symmetry, contrast, harmony, placement and repetition. Meanwhile, design placements specified the amount, position and scale of each element. A total of 56 descriptors are defined to represent apparel profile. As for user profiles, it is depicted based on four categories of features, including facial, body, mental and contextual characteristics, with 35 parameters listed. In future work, the entire identified descriptors will be evaluated through sensitivity analysis to interpret the correlations and degree of importance of each parameter. Eventually, a final representative feature set of apparel and users are going to be used to construct intelligent knowledge recommendation model with machine learning algorithms.

\begin{tabular}{|c|c|c|c|c|}
\hline Apparel profiles & Lines \& shapes & Colours & Patterns/prints & Textures \\
\hline Nature features & $\begin{array}{l}\mathrm{S}_{1} \text {-pocket type } \\
\mathrm{S}_{2} \text {-pocket number/ } \\
\text { position } \\
\mathrm{S}_{3} \text {-breast design } \\
\mathrm{S}_{4} \text {-fastening } \\
\mathrm{S}_{5} \text {-buttons } \\
\mathrm{S}_{6} \text {-hem geometry } \\
\mathrm{S}_{7} \text {-hem length } \\
\mathrm{S}_{8} \text {-silhouette } \\
\mathrm{S}_{9} \text {-fit } \\
\mathrm{S}_{10} \text {-collar type } \\
\mathrm{S}_{11} \text {-collar size } \\
\mathrm{S}_{12} \text {-sleeve type } \\
\mathrm{S}_{13} \text {-sleeve length } \\
\mathrm{S}_{14} \text {-vent position }\end{array}$ & $\begin{array}{l}\mathrm{C}_{1} \text {-colour system } \\
\mathrm{C}_{2} \text {-hue }\left(\mathrm{H}_{\text {hue }}\right) \\
\mathrm{C}_{3} \text {-hue attributes } \\
\mathrm{C}_{4} \text {-value }\left(\mathrm{V}_{\text {value }}\right) \\
\mathrm{C}_{5} \text {-chroma }\left(\mathrm{C}_{\text {chroma }}\right) \\
\mathrm{C}_{6} \text {-hue warmth } \\
\mathrm{C}_{7} \text {-undertone warmth }\end{array}$ & $\begin{array}{l}\mathrm{P}_{1} \text {-pattern/print } \\
\mathrm{P}_{2} \text {-colour schemes } \\
\mathrm{P}_{3} \text {-warmth } \\
\mathrm{P}_{4} \text {-shapes nature } \\
\mathrm{P}_{5} \text {-size } \\
\mathrm{P}_{6} \text {-number }\end{array}$ & $\begin{array}{l}T_{1} \text {-nature of fibres } \\
T_{2} \text {-name } \\
T_{3} \text {-structure } \\
T_{4} \text {-finished } \\
T_{5} \text {-transparency } \\
T_{6} \text {-thickness } \\
L_{7} \text {-weight } \\
T_{8} \text {-tactile }\end{array}$ \\
\hline $\begin{array}{l}\text { Design } \\
\text { Organizations }\end{array}$ & $\begin{array}{l}\mathrm{S}_{15} \text {-proportion } \\
\mathrm{S}_{16} \text {-symmetry }\end{array}$ & $\begin{array}{l}\mathrm{C}_{8} \text {-proportion } \\
\mathrm{C}_{9} \text {-symmetry } \\
\mathrm{C}_{10} \text {-contrast } \\
\mathrm{C}_{11} \text {-harmony }\end{array}$ & $\begin{array}{l}\mathrm{P}_{7} \text {-repetition } \\
\mathrm{P}_{8} \text {-placement } \\
\mathrm{P}_{9} \text {-contrast } \\
\mathrm{P}_{10} \text {-harmony } \\
\mathrm{P}_{11} \text {-proportion } \\
\mathrm{P}_{12} \text {-symmetry }\end{array}$ & $T_{9}$-contrast \\
\hline $\begin{array}{l}\text { Design } \\
\text { placements }\end{array}$ & N/A & $\begin{array}{l}\mathrm{C}_{12} \text {-colour combinations } \\
\mathrm{C}_{13} \text {-position } \\
\mathrm{C}_{14} \text {-scale }\end{array}$ & $\begin{array}{l}\mathrm{P}_{13} \text {-position } \\
\mathrm{P}_{14} \text {-scale }\end{array}$ & $\begin{array}{l}\mathrm{T}_{10} \text {-material types } \\
\mathrm{T}_{11} \text {-position } \\
\mathrm{T}_{12} \text {-size }\end{array}$ \\
\hline Total & 16 & 14 & 14 & 12 \\
\hline
\end{tabular}

\begin{tabular}{lllll}
\hline User profiles & Facial features & Body features & Style preferences (tastes) & Wearing occasions \\
\hline Nature features & $\mathrm{F}_{1}$-face shape & $\mathrm{B}_{1}$-body shape & $\mathrm{SP}_{1}$-casual/formal & $\mathrm{O}_{1}$-dating \\
& $\mathrm{F}_{2}$-hair style & $\mathrm{B}_{2}$-height & $\mathrm{SP}_{2}$-modern/classic & $\mathrm{O}_{2}$-wedding \\
& $\mathrm{F}_{3}$-eye colour & $\mathrm{B}_{3}$-weight & $\mathrm{SP}_{3}$-trendy/timeless & $\mathrm{O}_{3}$-interview \\
& $\mathrm{F}_{4}$-skin colour & $\mathrm{B}_{4}$-BMI & $\mathrm{SP}_{4}$-bright/dark & $\mathrm{O}_{4}$-conference \\
& $\mathrm{F}_{5}$-facial wear & & $\mathrm{SP}_{5}$-arousal/peaceful & $\mathrm{O}_{5}$-business \\
(glasses) & & $\mathrm{SP}_{6}$-summer spring/winter fall & $\mathrm{O}_{6}$-party \\
& $\mathrm{F}_{6}$ - beard & & $\mathrm{SP}_{7}$-feminine/masculine & $\mathrm{O}_{7}$-prom \\
& & $\mathrm{SP}_{8}$-youthful/mature & $\mathrm{O}_{8}$-funeral \\
& & $\mathrm{SP}_{9}$-smart/bold & $\mathrm{O}_{9}$-everyday \\
& & $\mathrm{SP}_{10}$-forceful/pleasurable & \\
& & $\mathrm{SP}_{11}$-decorative/austere & \\
& & $\mathrm{SP}_{12}$-luxuriant/ordinary & \\
\hline Table 7 The descriptive codes of the apparel and user profiles & $\mathrm{SP}_{13}$-fashionable/ conservative & \\
\hline
\end{tabular}

The values of each parameter are also specified. Table 8 gives an example of formulating values in each parameter of design organizations and placements of patterns/prints. Patterns are formed by repeating block(s) on a large surface, and prints are a unique pattern as a piece of art in itself. Pattern and print are sort of decorations of a plain surface with colour and shape together designed from two dimensions. Patterns show complex combinations of colours and shapes to express a motif. The colour schemes and nature of shapes are 
the most significant parameters to be specified (Fernandez, 2009). In design organizations, repetition $\left(\mathrm{P}_{7}\right)$ and placement $\left(\mathrm{P}_{8}\right)$ of colours and shapes reflect the structure of a pattern. Its values are defined with reference to Russell (2011) 's research of the fundamentals of printed textile design. Contrast $\left(\mathrm{P}_{9}\right)$ and harmony $\left(\mathrm{P}_{10}\right)$ mostly demonstrate the colour schemes of a pattern, with values identified referring to colour theory research (Wong, 1987, Volpintesta, 2014, Kopacz, 2003). In the relationship of pattern and colour, especially, for those styles which combine patterned and plain colours, they are also considered in placements features in terms of position and scale of patterned or plane colour (s).

\begin{tabular}{|c|c|}
\hline \multicolumn{2}{|c|}{ Organizations of Patterns /Prints } \\
\hline $\mathrm{P}_{7}$-repetition & $\begin{array}{l}\text { Block repeat/ half drop repeat/ brick repeat/ spot repeat/ } \\
\text { sateen repeat/ turnover or mirror repeat/ border/ repeat size }\end{array}$ \\
\hline$P_{8}$-placement & Motif or element/ all-over/ multidirectional/ bi-directional \\
\hline $\mathrm{P}_{9}$-contrast & $\begin{array}{l}\text { Hue/ light-dark/ cold-warm/ complementary/ simultaneous/ saturation/ } \\
\text { extension }\end{array}$ \\
\hline $\mathrm{P}_{10}$-harmony & $\begin{array}{l}\text { Monochromatic/Analogous/Complementary/Double complementary/Split } \\
\text { complementary/Double split complementary/Triad/ Tetradic }\end{array}$ \\
\hline $\mathrm{P}_{11}$-proportion & Ratio of area of all colour blocks \\
\hline $\mathrm{P}_{12}$-symmetry & Symmetry/asymmetry \\
\hline \multicolumn{2}{|c|}{ Placements of Patterns/Prints } \\
\hline $\mathrm{P}_{13}$-position & $\begin{array}{l}\text { Full patterned/printed colours } \\
\text { Full plane colours (see above section of colour) } \\
\text { Mixed: Patterned colours \& single hue/ single hue (share hue)/multi hues/ } \\
\text { Achromatics (no hue)/ Neutrals }\end{array}$ \\
\hline $\begin{array}{l}\mathrm{P}_{14} \text {-scale of } \\
\text { patterned/plane } \\
\text { colour(s) }\end{array}$ & $\begin{array}{l}\text { Front panel/side panel /back panel/chest/sleeves/cuffs/ } \\
\text { collar/shoulder/ edges/pockets/hoods/buttons/full shapes }\end{array}$ \\
\hline
\end{tabular}

\section{Conclusion}

This paper conducted a comprehensive review of academic publications in the field of apparel recommendation system. In order to elaborate this specific field, the research context and backgrounds were extended to the hightech integrations in apparel design and retailing markets. Through the thorough investigations of apparel recommendation systems, four types of models or systems are classified with respective key functions: clothes searching/retrieval, wardrobe recommendations, fashion coordination and intelligent recommendation systems. The working principle of the former two models is styles form feature similarity comparisons between new products and the previous liked products or wardrobe usage history. The latter two models are advanced in styles knowledge learning in matching style forms and meanings with individual features. Many studies were focused on system modelling utilizing various machine learning algorithms, such as Neural Networks and Support Vector Machine et.al. We found the research gaps in the expositions of both apparel and user profiles. Therefore, based on the reviewed work, we propose a comprehensive set of apparel and user profile features to advance a future system.

In the future, academic researches in developing such innovative systems need to be examined in practice to see the contributions to commercial markets. For different markets, it could split in short-term and long-term recommendations in the future research. Current discussions and reviews are all based on short-term recommendations toward apparel retailing markets. It delivers real-time recommendations straight to the online shoppers as shopping advice and suggestions. Apart from online shopping, recommendations could also be utilized in design and manufacture by providing long term recommendations, such as predicting new trends through years and seasons. In a word, engaging with real markets and users is the key for a realistic and practical recommendation system even though in research stage. 


\section{Reference}

3D-A-PORTER. 2012. 3D BODY SCANNING [Online]. UK. Available: http://3d-a-porter.com/ - about [Accessed 28 August 2014].

AKABANE, T., KOSUGI, S., KIMURA, S. \& ARAI, M. Method to consider familiarity in clothing coordination recommender systems. 2011 3rd International Conference on Computer Research and Development, 2011.

AMAZON. 1996. Your Amazon [Online]. Available: http://www.amazon.com/ [Accessed 11 September 2014].

ASHDOWN, S. P., CHOI, M. S. \& MILKE, E. 2008. Automated side-seam placement from 3D body scan data. International Journal of Clothing Science and Technology, 20, 199-213.

ASKASTYLIST. 2010. Need Help Figuring Out What to Wear? There's a (Glamour) App for That: Introducing "Ask a Stylist." [Online]. Available: http://www.glamour.com/fashion/blogs/dressed/2010/04/introducing-the-glamour-ask-a [Accessed 8 June 2015].

ASOS. 2014. Meet the stylists [Online]. Available: http://www.asos.com/discover/personalstylist?CTARef=HP\%7Cgen\%7Cbottom\%7Casos-stylists [Accessed 11 November 2014].

AU, K.-F., CHOI, T.-M. \& YU, Y. 2008. Fashion retail forecasting by evolutionary neural networks. International Journal of Production Economics, 114, 615-630.

BAUKJEN. 2014. e-stylist [Online]. Available: http://www.baukjen.com/uk/customer/estylist [Accessed 11 November 2014].

BESTYLEDUK. 2014. Personal styling [Online]. UK. Available: http://www.bestyleduk.com/personal-styling/ [Accessed 28 August 2014].

BORRAS, A., TOUS, F., LLADOS, J. \& VANRELL, M. 2003. High-Level Clothes Description Based on Colour-Texture and Structural Features. Pattern Recognition and Image Analysis, 2652, 108-116.

CHAN, A. P., FAN, J. \& YU, W. M. 2005. Prediction of men's shirt pattern based on 3D body measurements. International Journal of Clothing Science and Technology, 17, 100-108.

CHEN, Y., ZENG, X., HAPPIETTE, M., BRUNIAUX, P., NG, R. \& YU, W. 2008. A new method of ease allowance generation for personalization of garment design. International Journal of Clothing Science and Technology, 20, 161-173.

CHENG, C. I. \& LIU, D. S. 2008. An Intelligent clothes search system based on fashion styles International Conference on Machine Learning and Cybernetics. P.R.China: IEEE

CHO, Y., OKADA, N., PARK, H., TAKATERA, M., INUI, S. \& SHIMIZU, Y. 2005. An interactive body model for individual pattern making. International Journal of Clothing Science and Technology, 17, 91-99.

CHO, Y. S., KOMATSU, T., TAKATERA, M., INUI, S., SHIMIZU, Y. \& PARK, H. 2006. Posture and depth adjustable 3D body model for individual pattern making. International Journal of Clothing Science and Technology, 18, 96-107.

DAANEN, H. \& HONG, S.-A. 2008. Made-to-measure pattern development based on 3D whole body scans. International Journal of Clothing Science and Technology, 20, 15-25.

DAI, H. Q. The Research on Intelligent Clothing Recommendation System Based on Ontology. Advanced Materials Research, 2011. Trans Tech Publ, 827-831.

DAI, W. 2015. Clothing Fashion Style Recommendation System. NORTHEASTERN UNIVERSITY.

DONG, A. H., SHAN, D., RUAN, Z., ZHOU, L. Y. \& ZUO, F. 2013. The Design and Implementation of an Intelligent Apparel Recommend Expert System. Mathematical Problems in Engineering, 2013, 1-8.

DRESSIPI. 2011. Colthes you'll love perfect for you shape and style [Online]. Available: http://dressipi.com/ [Accessed 11 November 2014].

DRESSLI. 2014. Chat with any stylist for free advice. Shop with your own personal stylist. [Online]. Available: http://dress.li/ [Accessed 8 June 2015].

DUMELIIC, B., LARSON, M. \& BOZZON, A. Moody closet: exploring intriguing new views on wardrobe recommendation. Proceedings of the First International Workshop on Gamification for Information Retrieval, 2014. ACM, 61-62.

E-TAILOR 2002. Integration of 3D body measurement, Advanced CAD, and E-commerce technologies in the European fashion industry.

EICHER, J. B., AUTHOR. \& EVENSON, S. L., AUTHOR. 2015. The visible self: global perspectives on dress, culture, and society, New York, Fairchild Books.

EMARKETER. 2015. PERSONALIZATION FOR RETAILERS ROUNDUP [Online]. Available: https://www.emarketer.com/public_media/docs/eMarketer_Personalization_Retailers_Roundup.pdf [Accessed 18 February 2016].

FERGUSON, R. B. 2013. How Analytics is Giving Fashion a Makeover [Online]. Available: http://sloanreview.mit.edu/article/how-analytics-is-giving-fashion-a-makeover/ [Accessed 18 February 2016].

FERNANDEZ, A. 2009. Fashion print design: from idea to final print, London, A. \& C. Black.

FIORE, A. M. 2010. Understanding Aesthetics for the Merchandising and Design Professional New York, Fairchild Books.

GOH, K. N., CHEN, Y. Y. \& LIN, E. S. 2011. Developing a Smart Wardrobe System. Consumer Communications and Networking Conference (CCNC). Las Vegas, NV IEEE.

GRAU, J. 2009. Personalized Product Recommendations: Predicting Shoppers' Needs [Online]. Available: http://twinklemagazine.nl/achtergronden/2009/05/EMarketer_Etailers_worstelen_met_aanbevelingen/eMarket er_personalization_report.pdf [Accessed 18 February 2016].

GROGAN, S., GILL, S., BROWNBRIDGE, K., KILGARIFF, S. \& WHALLEY, A. 2013. Dress fit and body image: a thematic analysis of women's accounts during and after trying on dresses. Body Image, 10, 380-8. 
GUO, Z., WONG, W., LEUNG, S. \& LI, M. 2011. Applications of artificial intelligence in the apparel industry: a review. Textile Research Journal, 81, 1871-1892.

HIDAYATI, S. C., CHENG, W.-H. \& HUA, K.-L. Clothing genre classification by exploiting the style elements. Proceedings of the 20th ACM international conference on Multimedia, 2012. ACM, 1137-1140.

HIX, C. 1981. How to dress your man, New York, Crown Publishers.

HOLMES, E. 2015. How Style Bloggers Earn Sales Commissions, One Click at a Time [Online]. Available: http://www.wsj.com/articles/how-style-bloggers-earn-sales-commissions-one-click-at-a-time-1423693911 [Accessed 10 February 2016].

HONG LU, Y. C., JINSONG DU 2013. An Interactive System Based on Kansei Engineering to Support Clothing Design Process. Research Journal of Applied Sciences, Engineering and Technology, 6, 4531-4535.

IWATA, T., WANATABE, S. \& SAWADA, H. Fashion coordinates recommender system using photographs from fashion magazines. IJCAI Proceedings-International Joint Conference on Artificial Intelligence, 2011. Citeseer, 2262.

JAGADEESH, V., PIRAMUTHU, R., BHARDWAJ, A., DI, W. \& SUNDARESAN, N. Large scale visual recommendations from street fashion images. Proceedings of the 20th ACM SIGKDD international conference on Knowledge discovery and data mining, 2014. ACM, 1925-1934.

JIN, W., GUODONG, L., LONG, C., YULEI, G. \& WEIYAN, D. 2010. Customer participating 3D garment design for mass personalization. Textile Research Journal, 81, 187-204.

JOHNLEWIS. 2001. Personal Styling service [Online]. UK. Available: http://www.johnlewis.com/our-services/fashion-adviceservice [Accessed 29 August 2014].

JONES, M. R. \& GIDDINGS, V. L. 2010. Tall women's satisfaction with the fit and style of tall women's clothing. Journal of Fashion Marketing and Management, 14, 58-71.

JUNG, J., MATSUBA, Y., MALLIPEDDI, R., FUNAYA, H., IKEDA, K. \& LEE, M. 2013. Evolutionary Programming based Recommendation system for online shopping. Signal and Information Processing Association Annual Summit and Conference (APSIPA). Kaohsiung IEEE.

KALANTIDIS, Y., KENNEDY, L. \& LI, L.-J. Getting the look: clothing recognition and segmentation for automatic product suggestions in everyday photos. Proceedings of the 3rd ACM conference on International conference on multimedia retrieval, 2013. ACM, 105-112.

KIM, D., KWON, Y.-B. \& PARK, J. 2013. A Scoring Model for Clothes Matching Using Colour Harmony and Texture Analysis. Graphics Recognition. New Trends and Challenges, 7423, 218-227.

KIM, H. \& DAMHORST, M. L. 2010. The Relationship of Body-Related Self-Discrepancy to Body Dissatisfaction, Apparel Involvement, Concerns With Fit and Size of Garments, and Purchase Intentions in Online Apparel Shopping. Clothing and Textiles Research Journal, 28, 239-254.

KIM, H. S. \& CHO, S. B. 2000. Application of interactive genetic algorithm to fashion design. Engineering Applications of Artificial Intelligence, 13, 635-644.

KIM, S. \& PARK, C. K. 2007. Basic garment pattern generation using geometric modeling method. International Journal of Clothing Science and Technology, 19, 7-17.

$\mathrm{KIM}, \mathrm{S}$.-J. Integration of environmental contexts and personal factors for coordinating garments: an environmental user interface paradigm to enrich user interactions. Proceedings of the 47th Annual Southeast Regional Conference, 2009. ACM, 59.

KOPACZ, J. 2003. Color in three-dimensional design, New York, McGraw-Hill.

LEAVITT, N. 2006. Recommendation Technology: Will It Boost E-Commerce? Computer, 39, 13-16.

LEE, J. Y., ISTOOK, C. L., NAM, Y. J. \& PARK, S. M. 2007. Comparison of body shape between USA and Korean women. International Journal of Clothing Science and Technology, 19, 374-391.

LENIUS, O. 1998. A well-dressed gentleman's pocket guide, London, Prion.

LI, J. \& LI, Y. 2012. Cognitive model based fashion style decision making. Expert Systems with Applications, 39, $4972-4977$.

LIKETOKNOW. 2016. Shop your favorite Instagrams [Online]. Available: http://liketoknow.it/ [Accessed 18 February 2016].

LIMAKSORNKUL, C., NAKORN, D. N., RAKMANEE, O. \& VIRIYASITAVAT, W. Smart Closet: Statistical-based apparel recommendation system. Student Project Conference (ICT-ISPC), 2014 Third ICT International, 2014. IEEE, 155158.

LIN, J. J. 2007a. A Case-Based Apparel Styling Classification Approach Using Genetic Algorithm. Journal of Applied Science and Engineering, 10, 243-252.

LIN, J. J. 2007b. Intelligent Decision Making Based on GA for Creative Apparel Styling. Journal of Information Science \& Engineering, 23, 1923.

LIU, N., CHOI, T. M., YUEN, M. C. \& NG, F. 2009. An exploratory study on expert system's applications in fashion Mass Customization. International Conference on Machine Learning and Cybernetics. Baoding: IEEE.

LIU, S., FENG, J., SONG, Z., ZHANG, T., LU, H., XU, C. \& YAN, S. Hi, magic closet, tell me what to wear! Proceedings of the 20th ACM international conference on Multimedia, 2012a. ACM, 619-628.

LIU, Y.-J., ZHANG, D.-L. \& YUEN, M. M.-F. 2010. A survey on CAD methods in 3D garment design. Computers in Industry, 61, 576-593.

LIU, Z., WANG, J., CHEN, Q. \& LU, G. 2012b. Clothing similarity computation based on TLAC. International Journal of Clothing Science and Technology, 24, 273-286.

LU, H., CHEN, Y. \& DAI, H.-Q. 2013. Clothing recommendation based on fuzzy mathematics. International Journal of Advanced Operations Management 9, 5, 14-30. 
MACKIE, A., AUTHOR., COBB, B., EDITOR OF COMPILATION. \& HACK, J., EDITOR OF COMPILATION. 2014. Another man: men's style stories, New York, Rizzoli.

MALLZEE. 2012. Shop the high street in your hand [Online]. Available: http://mallzee.com/ - / [Accessed 8 June 2015].

MASUKO, S. \& HAYASHI, Y. KiTeMiROOM: a fashion-coordination system for mobile devices. CHI'13 Extended Abstracts on Human Factors in Computing Systems, 2013. ACM, 601-606.

METAIL. 2012. Create any body. Try on anything. Share everything [Online]. Available: http://metail.com/ [Accessed 10 June 2015].

MIURA, S., YAMASAKI, T. \& AIZAWA, K. SNAPPER: Fashion Coordinate Image Retrieval System. Signal-Image Technology \& Internet-Based Systems (SITIS), 2013 International Conference on, 2013. IEEE, 784-789.

MOK, P. Y., XU, J., WANG, X. X., FAN, J. T., KWOK, Y. L. \& XIN, J. H. 2013. An IGA-based design support system for realistic and practical fashion designs. Computer-Aided Design, 45, 1442-1458.

MPAMPA, M. L., AZARIADIS, P. N. \& SAPIDIS, N. S. 2010. A new methodology for the development of sizing systems for the mass customization of garments. International Journal of Clothing Science and Technology, 22, 49-68.

NA, Y. \& AGNHAGE, T. 2013. Relationship between the preference styles of music and fashion and the similarity of their sensibility. International Journal of Clothing Science and Technology, 25, 109-118.

NAGAO, S., TAKAHASHI, S. \& TANAKA, J. 2008. Mirror Application: recommendation of clothes coordination in daily life. HFT, 367-374.

NETFLIX. 1997. DVD NETFLIX [Online]. Available: https://dvd.netflix.com/ [Accessed 11 September 2014].

NETROBE. 2011. Celebrate your style inspire others [Online]. Available: https://netrobe.com/ [Accessed 8 June 2015].

NOSTO. 2011. Personalized Product Recommendations [Online]. Available: http://www.nosto.com/features/productrecommendations/ [Accessed 18 February 2016].

PARK, J., NAM, Y., CHOI, K.-M., LEE, Y. \& LEE, K.-H. 2009. Apparel consumers' body type and their shopping characteristics. Journal of Fashion Marketing and Management, 13, 372-393.

PETRAK, S. \& ROGALE, D. 2006. Systematic representation and application of a 3D computer-aided garment construction method: Part I: 3D garment basic cut construction on a virtual body model. International Journal of Clothing Science and Technology, 18, 179-187.

POLYVORE. 2007. Polyvore is a shopping site and app where you can give and get styling ideas from one of the world's largest style community [Online]. Available: http://www.polyvore.com/ [Accessed 18 February 2016].

RAJARAMAN, A. \& ULLMAN, J. D. 2011. Recommendation Systems. Mining of Massive Datasets. Cambridge University Press

ROBSON, C., MAHARIK, R., SHEFFER, A. \& CARR, N. 2011. Context-aware garment modeling from sketches. Computers \& Graphics, 35, 604-613.

ROETZEL, B. \& BEER, G. 2009. Gentleman: a timeless guide to fashion, Princes Risborough, h.f. ullmann.

RUSSELL, A. 2011. The fundamentals of printed textile design, Lausanne, AVA Academia.

SATAM, D., LIU, Y. \& LEE, H. J. 2011. Intelligent design systems for apparel mass customization. Journal of the Textile Institute, 102, 353-365.

SEKOZAWA, T., MITSUHASHI, H. \& OZAWA, Y. 2011. One to One Recommendation System in Apparel Online Shopping. Electronics and Communications in Japan, 94, 51-60.

SHEN, E., LIEBERMAN, H. \& LAM, F. 2007. what am I Gonna Wear?: Scenario-Oriented Recommendation. International Conference on Intelligent User Interfaces. USA.

SHUXIA, W., SHENGFENG, Q. \& CONGYING, G. 2014. Feature-Based Human Model for Digital Apparel Design. Automation Science and Engineering, IEEE Transactions on, 11, 620-626.

SIMILARWEB. 2016. Traffic overview of the Style Seek [Online]. Available: http://www.similarweb.com/website/styleseek.com [Accessed 18 February 2016].

SIMPLE, C. \& HOCHSWENDER, W. 1998. Men's wardrobe, London, Thames \& Hudson.

STITCHFIX. 2011. Clothing and accessories hand-selected by a personal stylist, delivered to your door. [Online]. Available: https://www.stitchfix.com/ [Accessed 8 June 2015].

STUDIO, P. 2013. Is personal styling the next big thing for online fashion? [Online]. Available: http://poqstudio.com/2013/03/is-personal-styling-the-next-big-thing-for-online-fashion/ [Accessed 10 June 2015].

STYLEBOOK. 2009. The Stylebook Concept [Online]. Available: http://www.stylebookapp.com/about.html [Accessed 8 June 2015].

STYLEDOCTORS. 2004. Style Doctors Personal Stylists [Online]. Available: http://styledoctors.com/ [Accessed 8 June 2015].

STYLEMATIC. 2013. Stylematic is a pocket stylist that delivers personal fashion recommendations [Online]. Available: http://stylematic.co/ [Accessed 6 June 2015].

STYLESEEK. 2015. A curated shopping site based on your personal style [Online]. Available: https://www.styleseek.com/what-is-styleseek [Accessed 8 June 2015].

STYLEUP. 2012. Your taste is personal. Shouldn't your fashion magazine be? [Online]. Available: http://www.thestyleup.com/home?next=/ [Accessed 19 February 2016].

SUL, I. H. \& KANG, T. J. 2006. Interactive garment pattern design using virtual scissoring method. International Journal of Clothing Science and Technology, 18, 31-42.

TC $^{2}$. 2011. 3D Body Scanning \& Technology Development [Online]. Available: http://www.tc2.com/index_3dbodyscan.html [Accessed 10 September 2014]. 
THECHAPAR. 2013. Hand-picked clothing for men [Online]. Available: http://www.thechapar.com/ [Accessed 8 June 2015]. TOKUMARU, M., MURANAKA, N. \& IMANISHI, S. 2003. Virtual Stylist Project-Examination of Adapting Clothing Search System to User's Subjectivity with Interactive Genetic Algorithms. The 2003 Congress on Evolutionary Computation. IEEE

TRUNKCLUB. 2013. Your personal stylist will find the best clothes to fit your style, budget, and existing wardrobe. [Online]. Available: https://www.trunkclub.com/ [Accessed 18 February 2016].

TSUJITA, H., TSUKADA, K., KAMBARA, K. \& SIIO, I. 2010. Complete Fashion Coordinator: A support system for capturing and selecting daily clothes with social networks. International Conference on Advanced Visual Interfaces USA: ACM.

TU, Q. Q. \& DONG, L. 2010. An Intelligent Personalized Fashion Recommendation System. International Conference onCommunications, Circuits and Systems (ICCCAS). Chengdu: IEEE

TURQUIN, E., WITHER, J. \& HUGHES, J. F. 2007. A sketch-based interface for clothing virtual characters. . Computer Graphics and Applications, 27, 72-81.

VOGIATZIS, D., PIERRAKOS, D., PALIOURAS, G., JENKYN-JONES, S. \& POSSEN, B. J. H. H. A. 2012. Expert and community based style advice. Expert Systems with Applications, 39, 10647-10655.

VOLPINTESTA, L., AUTHOR. 2014. The language of fashion design: 26 principles every fashion designer should know, Beverley, MA, Rockport Publishers.

VURUSKAN, A., INCE, T., BULGUN, E. \& GUZELIS, C. 2015. Intelligent fashion styling using genetic search and neural classification. International Journal of Clothing Science and Technology, 27, 283-301.

WANG, Y., CHEN, Y. \& CHEN, Z.-G. 2008. The sensory research on the style of women's overcoats. International Journal of Clothing Science and Technology, 20, 174-183.

WIDHADH. 2012. Why boutiques.com shut down (remember that google product?) - you're not alone in forgettin [Online]. Available: http://widhadh.com/why-boutiques-com-shut-down-remember-that-google-product-youre-not-alonein-forgetting-it/ [Accessed 18 February 2016].

WONG, W. 1987. Principles of color design, New York, Van Nostrand Reinhold.

WONG, W. K., ZENG, X. H. \& AU, W. M. R. 2009a. A decision support tool for apparel coordination through integrating the knowledge-based attribute evaluation expert system and the T-S fuzzy neural network. Expert Systems with Applications, 36, 2377-2390.

WONG, W. K., ZENG, X. H., AU, W. M. R., MOK, P. Y. \& LEUNG, S. Y. S. 2009b. A fashion mix-and-match expert system for fashion retailers using fuzzy screening approach. Expert Systems with Applications, 36, 1750-1764.

XIAO-SONG, H., LI-LING, J., RUI, C., TIE-JUN, W. \& QING, L. A probabilistic clothes recommender based on clothes features. Management Science \& Engineering (ICMSE), 2014 International Conference on, 2014. IEEE, 76-81.

YAMADA, T. \& TAKAMI, K. 2012. Configuration of the System for a Fashion Coordination Service Based on Clothes Life Logs. TENCON 2012 - 2012 IEEE Region 10 Conference. Cebu IEEE.

YAN, J. L., SHEN, Z., KAZIUNA, E. \& ZHAO, L. J. 2011a. Socially-Interactive Dressing Room An Iterative Evaluation on Interface Design. $\mathrm{CHI}$ '11 Extended Abstracts on Human Factors in Computing Systems USA: ACM.

YAN, J. L., ZHOU, S., KAZIUNAS, E. \& ZHAO, L. J. 2011b. Socially-Interactive Dressing Room: An Iterative Evaluation on Interface Design. The ACM CHI Conference on Human Factors in Computing Systems. Canada.

YANG, Y., ZHANG, W. \& SHAN, C. 2007. Investigating the development of digital patterns for customized apparel. International Journal of Clothing Science and Technology, 19, 167-177.

YASSEEN, Z., NASRI, A., BOUKARAM, W., VOLINO, P. \& MAGNENAT-THALMANN, N. 2013. Sketch-based garment design with quad meshes. Computer-Aided Design, 45, 562-567.

YINGGANG, X., ZHILIANG, W. \& QING, Z. Humanized clothing recommendation system based on fuzzy set theory. Control Conference, 2007. CCC 2007. Chinese, 2007. IEEE, 380-385.

YU-CHU, L., KAWAKITA, Y., SUZUKI, E. \& ICHIKAWA, H. 2012. Personalized Clothing-Recommendation System Based on a Modified Bayesian Network. 414-417.

YUNCHU, Y. \& WEIYUAN, Z. 2007. Prototype garment pattern flattening based on individual 3D virtual dummy. International Journal of Clothing Science and Technology, 19, 334-348.

ZENG, X., KOEHL, L., WANG, L. \& CHEN, Y. 2013. An Intelligent Recommender System for personized fashion design. IFSA World Congress and NAFIPS Annual Meeting (IFSA/NAFIPS). Edmonton, AB IEEE.

ZHANG, W., BEGOLE, B., CHU, M., LIU, J. \& YEE, N. 2008. REAL-TIME CLOTHES COMPARISON BASED ON MULTI-VIEW VISION. International Conference on Distributed Smart Cameras. Stanford, CA IEEE 